\title{
Ethical Legislative, Policy Framework and Ethical Hiring: A Survey of Selected Organizations in Kenya
}

\author{
Dr. Hellen Wothaya Sang \\ School of Business and Economics, University of Kabianga, P.O. Box 2030-20200, Kericho, Kenya
}

\begin{abstract}
For most businesses their main concern is profit with little emphasis being laid on ethics. Ethics in business can be improved by having legislation and policies that provide ethical guiding principles. Laws providing ethical guidelines as well as organizational ethical code of conduct are meant to provide ethical guidelines to managers when making decisions. All Human Resource practices should be based on an ethical foundation, this is especially critical when making hiring decisions. This paper sought to establish the relationship between ethical legislative, policy framework and ethical hiring practices in organization. The study employed a correlational research design, and had a target population of $67 \mathrm{HR}$ practitioners. A sample size of 42 respondents was selected; data was collected through the use of questionnaires. The Questionnaires were tested for reliability and validity, and the data collected was analyzed using descriptive and inferential statistics and presented using tables and charts. The empirical findings of the study obtained a Pearson correlation coefficient of 0.693 , an R square value of 0.480 and a p-value of 0.000 . The study concludes that ethical legislative and policy framework has a positive and significant relationship with ethical hiring practices. The study recommends that managers should follow the laid down ethical laws and policies which can guide them in making ethical hiring decisions.
\end{abstract}

Keywords: Ethics, ethical hiring, ethical Legislative and policy framework, Ethical laws, code of ethics

DOI: $10.7176 / \mathrm{EJBM} / 11-15-08$

Publication date:May $31^{\text {st }} 2019$

\subsection{Introduction}

Recruitment involves getting many qualified people to apply for vacant positions in an organization while the involves using specific instruments to choose the best candidate from a pool of job applicants (Bratton and Gold (2007). According to Ouma (2017) in a study on "Ethical leadership and organizational culture", ethics are the rules that people apply when making decisions on what is right or wrong. Ethics acts as the basis for creating ethical standards and ethical practices which are critical for the success of an organization.

According to Ouma (2017) some the factors that influence ethical behaviour include; laws and legal procedures where the fear of prosecution acts as a deterrent from engaging in unethical behaviour and organizational factors such as organizational code of ethics or code of conduct as well as policy statements on ethical standards. According to International Federation of Accountants (IFAC. 2007), many organizations prefer to have a published code of ethics so as to guide ethical conduct.

According to a CIPD research report (2015), "on developing principles for the profession", HR professionals are expected to use their specialist knowledge for the benefit of the organization and any other relevant stakeholder. HR professionals are meant to design, implement and manage HR processes that bring the most benefit to the organization and the stakeholders that they serve. HR professionals are meant to provide their professional perspectives on how to manage people for sustainable development of the organization. This implies that they should design, implement and management HR practices and procedures that provide the best benefit to the organizations and the society at large. One of the HR functional areas that they should endeavor to ensure it is managed in an ethical manner is that of recruitment and selection.

Ethics are crucial during recruitment and selection. This is because, according to Gommans and Musumbu (2014) introduction to ethical or unethical behaviour in an organization starts at the hiring stage, this is because it is at this stage that an employee gets introduced to the ethical or unethical values and culture within an organization. According to Murage, Sang and Ngure (2018) in a research paper on "Ethical Issues in Recruitment, Selection and Employee Performance in Public Universities in Nyeri County, Kenya", ethical hiring should be based on the principle of merit, fairness and transparency in the selection criteria

\subsection{Problem Statement}

The pressure for financial gains or short term goals at the expense of long terms sustainable goals has led to many unethical practices within organizations. According to researchers such as Gommans and Musumbu (2014) Initiation to ethical or unethical conduct starts at the hiring process, therefore the recruitment and selection process is critical in creating ethical organizations. However there are situations where HR professionals face ethical dilemmas and challenges during the hiring process or engage in unethical and unprofessional conduct during the recruitment and selection process where hiring is not based on merit, fairness or transparency. This research intends to explore the relationship between ethical legislative and policy framework and ethical hiring in organizations so 
as to ensure sustainable development within the organizations.

\subsection{Specific Objectives}

i. To identify the ethical hiring practices in selected organizations in Kenya

ii. To establish the effect of Legislative and policy frameworks on ethical hiring practices in selected organizations in Kenya

\subsection{Research Hypothesis}

i. A legislative and policy framework has no significant effect on ethical hiring practices in selected organizations in Kenya

\subsection{Literature Review}

\subsection{Ethical Legislative and Policy Framework}

Ethics are the guidelines of what is acceptable or not acceptable, right or wrong which provide a framework for deciding on the appropriate or inappropriate behavior. This can be enhanced by having clear and explicit legislation and policies. According to Valentine, Hollingworth, Nam and Hall (2013), In a research paper on "Ethical Context and Ethical Decision Making" legislation and policies help to create an ethical context that can help in ethical decision making. HR professionals in Kenya are guided by the IHRM Act of 2012, which is an Act of parliament that provides for the establishment of Institute of Human Resource Management, a HR professional body which among other functions, also plays a key function of establishing and regulating standards and code of conduct for HR professionals. This is by disciplining members who engage in any form of professional misconduct such as not following laid down policies and procedures or engaging in any negative practices such as any form of unfairness or impartiality among others. In addition the HR professionals also have ethical codes of conduct in the organizations they serve and HR policies and manuals that give them guidance when discharging their duties. However despite this many HR professional faces many ethical dilemmas as they discharge their HR duties, especially in the area of recruitment and selection.

Ethics committees in organizations can help to offer advice on ethical issues when managers are faced with ethical dilemmas, by helping the organization to establish policies on ethics as well as by advising management on ethical issues and overseeing the enforcement of ethical code of conduct. The committee can also manage "Ethics Hot Lines" so as to encourage whistle blowing, so that when employees are troubled about some ethical issue but are afraid to raise it with their immediate supervisor, they can be assured that a member of the ethics committee will treat their concern confidentially and investigates the situation.

Under the Kenyan Law, there is a Leadership and Integrity Act, which is meant to provide ethical guidelines and procedures to public officers as they discharge their duties and serve the citizenry. Some of the laws and policies that can guide ethical hiring include laws and policies on; non discrimination and impartiality, declaring conflict of interest, following the laid doing policies and procedures, performing duties honestly and transparently, following the ethical and professional requirements of the professional body to which they belong to mention a few.

All these laws and policies help to provide for a legislative and policy framework that can help to ensure ethical standards are maintained in organizations by institutionalizing ethics. However inspite of these laws Kenya has been ranked as one of the most corrupt countries by Transparency International. From a report by the Ethics and Anti Corruption Commission report of 2014 and 2016 (EACC, 2014, 2016) Corruption perception nationally and at county level stood at 39.4\% and 25.9\%: respectively in 2014, however it increased to 79.3 in 2016.

According to Creighton as cited by Pinnington, Macklin and Campbel (2007) in their book "Human Resource Management: Ethics and Employment" no laws can comprehensively "enforce ethical behaviour" they can only provide a framework that can encourage ethical behaviour and act as an incentives for those who act in an ethical manners while providing a means of redress for those who have been subjected to unethical treatment.

\subsection{Ethical Hiring}

Hiring is said to be ethical when it follows the laid down policies and procedures and results in hiring that based on merit and fairness, where the person hired fits the job. According to Wheeler (2004), some of the unethical recruiting and selection practices include; include how a position is represented to a candidate, how candidates are located, and how interviews are conducted. HR professionals need to focus more on ethics when recruiting, selecting, and placing job candidates into organizational roles, as well as provide realistic job previews. Selection process should also include honesty testing, and ethics-based interviewing approaches so as to hire employees that are ethics conscious and can fit within the organizations ethical environment, (Karren and Zacharias, 2007). Leaders also need to develop policies that enhance ethical context and encourage employees to act ethically on the job. For example, the creation of codes of conduct, which provide behavioral guidelines to workers, and ethics training, which teaches the different ethical issues that employees can possibly face, can help establish a prevailing 
sense of ethics in the workplace

According to Alder and Gilbert (2006), hiring practices are legally defensible if they are used to assess all candidates and effectively predict which candidates will best perform the job. In a study by Ikwesi as cited by Onyeaghala and Hyacinth (2016) on the effects of recruitment and selection procedures on the efficiency of the public service in Nigeria, a descriptive survey design was applied and the major findings revealed that: recruitment and selection procedures in public service are not strictly followed; politicization and other informal processes dominate the established recruitment and selection procedures. Merit does not always count to secure employment in public service rather the use of federal character, quota system, indigene-ship, son of soil syndrome, etc. are mostly considered. Also, there was an established relationship between inefficiency of the Nigerian public service and weak recruitment and selection processes.

There is also a current trend of unethical global recruitment e.g. among health professionals by not giving employees contracts, or the terms and conditions of work being different from those in the contracts, use of collaterals, expensive fees by international recruitment agencies and low pay for the foreign employees. According to a report by UNODC (2015) recruitment agencies have also been known to engage in unethical recruiting practices such as charging high recruitment fees for recruitment services as well as engaging in fraudulent practices such as exploitative labour practices and human trafficking. According to Boardman and Barbato (2008), in a review of socially responsible HR and labour relations practice in international hotel chains, ethical recruitment and selection practices should result in the hiring of employees with an excellent fit for the job. This is by ensuring there is an accurate advertisement with clear job/role descriptions and person specifications as well as context information; there is use of appropriate selection tools, criteria and mechanism and there is well planned induction.

According to Murage, Sang and Ngure (2018) unethical recruitment and selection is one that is based on nepotism, sexual harassment, discrimination and bribery where the employees selected lack the requisite right knowledge, skills, abilities, and competence. Their research findings show that there is a positive significant relationship between ethical hiring and employee performance. According to Tordoff (2017) in a publication on "Ethical Recruitment Guidelines" ethical guidelines that should be followed during hiring involves; recruiters and potential employers following labour laws during recruitment, being transparent and providing clear and full disclosure of the terms and conditions of service before potential employees sign the employment contract, treating all job applicants in a fair, equal and respectful manner as well as only hiring people who have the capacity to deliver and have the right ethical values and attitudes. According to Ibid (2017) other ethical guidelines include; having a wide recruitment pool, being transparent about hiring decisions, using more than one method when making selection decisions, doing background checks on the successful potential employees and following ethical recruitment policies. According to Nguyen (2013) in a research paper on "Ethics in Employee Selection" it is important to ensure that hiring decisions are both legal and ethical.

\subsection{Research Methodology \\ 3.1 Research design}

A correlational research design was used to collect data from a cross section of private and public organizations. This research design was found to be appropriate because it is able to test the degree of association between two or more variables; hence it will assist to show the relationship between the variables of ethical hiring and ethical legislative or policy framework.

\subsection{Target population}

This research targeted three public organizations and one private organization located in Kericho and Nakuru counties in Kenya, East Africa. The target respondents were $67 \mathrm{HR}$ practitioners who take part in the hiring process in these four organizations. The organizations consisted of two county governments and two universities in Kericho and Nakuru counties.

\subsection{Sampling design}

Purposive sampling design was used to select the HR practitioners that are involved in the hiring process; these were 42 in number in the 4 selected organizations

\subsection{Data collection}

Data was collected through the use of questionnaires that contained mainly structured, close ended questions with a few open ended questions that helped to probe the respondents. The validity of the data collection tool was test by exposing it to HR and ethics experts who analyzed and gave their input. The reliability was assessed through use of the Chronbach alpha test, where values of 0.93 were obtained which was above the recommended threshold value of 0.7 . 


\subsection{Data analysis and presentation}

Data was mainly analyzed through the use of descriptive statistics and inferential statistics. Correlation and regression analysis was used to identify the relationship between the variables. The regression model used was $\mathrm{Y}=\mathrm{B}_{0}+\mathrm{B}_{1} \mathrm{X}_{1+\mathrm{e}}$

$\mathrm{Y}: \quad$ Ethical Hiring practices

$\beta_{0}: \quad$ constant (coefficient of intercept)

$\mathrm{X}_{1:} \quad$ Ethical Legislative and Policy framework

$\mathrm{B}_{1:} \quad$ Regression coefficient

Content analysis was used to analyze the open ended questions, and the data was presented through use of tables and charts.

\subsection{Results and Discussion}

There was a response rate of $93 \%$ with 39 questionnaires being returned out of the 42 that were administered.

\subsection{Descriptive analysis}

When the respondents were asked if Ethics and anti corruption laws have influenced ethical conduct during recruitment and selection $40 \%$ agreed while $26 \%$ strongly agreed, this shown in figure 1 . This implies that an ethical and legislative framework provides a guideline on the acceptable ethical behavior during hiring.

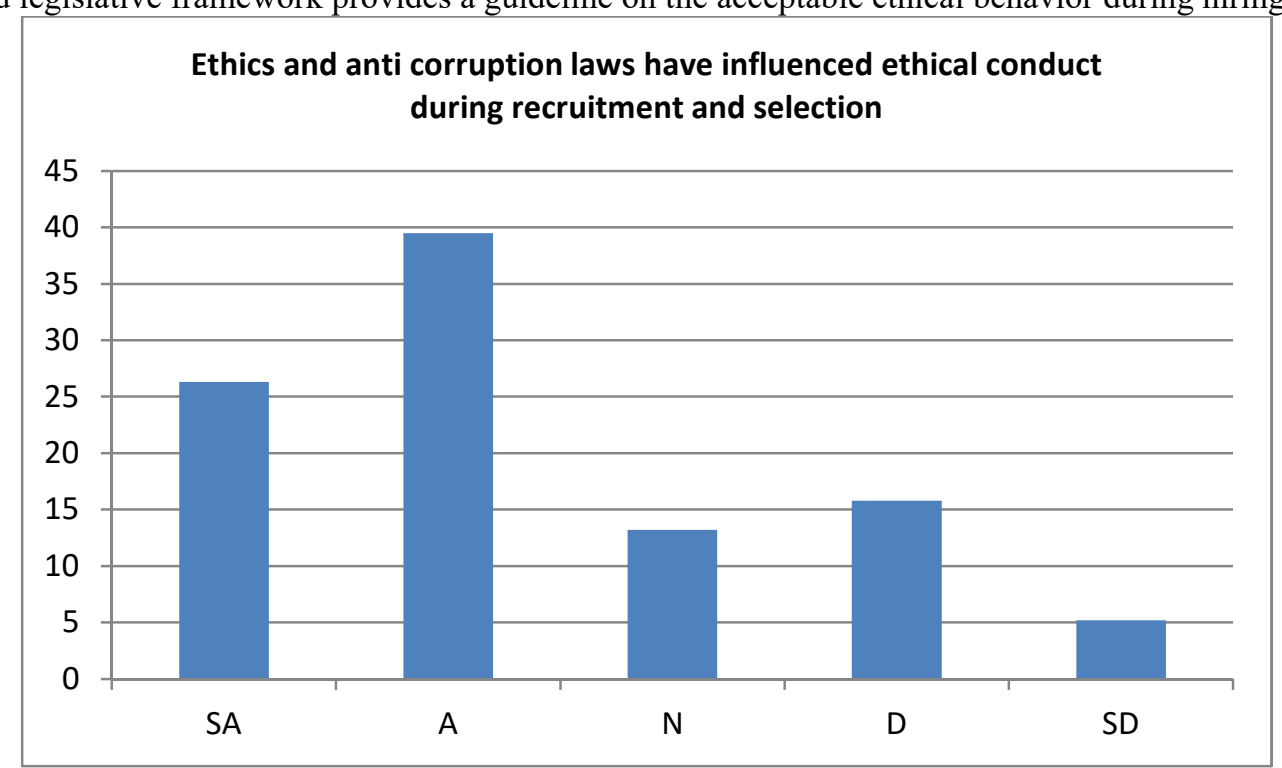

Figure 1

When the respondents were asked for their opinion on whether laws and policies have helped to create an ethical work environment $64 \%$ of them agreed (40\% strongly agreed while $28 \%$ agreed), as shown in figure 2 . These findings are in agreement with a research by Valentine, Hollingworth, Nam and Hall (2013), on "Ethical Context and Ethical Decision Making" which showed that legislation and policies help to create an ethical context that can help in ethical decision making.

\section{laws and policies on ethics have helped create an ethical work environment in my organization}
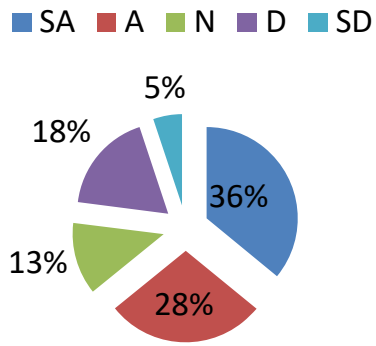

Figure 2 
The study also sought to establish the ethical hiring practices that were practiced in the sampled organizations. The data collected as shown in table 1 using likert scale, showed that majority of the respondent strongly agreed or agreed that documented hiring procedures are followed during recruitment and selection with $15 \%$ indicating that they are not strictly followed in their organization. $33.4 \%$ of the respondents disagreed $(23.1 \%$ disagreed while $10.3 \%$ strongly disagreed) that candidates that are shortlisted usually have the relevant qualifications and experience for the job while 59\% agreed (20.5\% strongly agreed and $38.5 \%$ agreed). Majority of the respondents $(61.5 \%)$ agreed that the same selection tool is used for all the candidates. $48.7 \%$ of the respondents agreed that Nepotism and tribalism is not a factor when hiring decisions are made while $41 \%$ disagreed. This implies that there are situations where there is a form of discrimination during hiring with $43.6 \%$ agreeing $(15,4 \%$ strongly agreeing and $28.2 \%$ agreeing) that Some candidates are hired without going through the formal recruitment and selection process. The findings of this study shows that majority of the respondents agreed that their organizations practiced ethical hiring with a few organizations practicing unethical hiring practices. This findings concur with a findings from a research by Murage, Sang and Ngure (2018) which showed that ethical hiring involves; subjecting all potential candidates to similar evaluation criteria, advertising all employment opportunities, adhering to well documented recruitment policy and code of ethics.

\section{Table 1: Responses on ethical hiring practices}

\begin{tabular}{|c|c|c|c|c|c|c|}
\hline Responses & $\begin{array}{l}\text { SA } \\
\%\end{array}$ & $\begin{array}{l}\mathrm{A} \\
\%\end{array}$ & $\begin{array}{l}\mathrm{N} \\
\%\end{array}$ & $\begin{array}{l}\mathrm{D} \\
\%\end{array}$ & $\begin{array}{l}\text { SD } \\
\%\end{array}$ & $\begin{array}{l}\text { To } \\
\text { tal }\end{array}$ \\
\hline $\begin{array}{l}\text { Documented recruitment and selection procedures are strictly followed in the } \\
\text { selection process }\end{array}$ & $\begin{array}{l}46 . \\
2\end{array}$ & $\begin{array}{l}30 \\
.8\end{array}$ & $\begin{array}{l}7 . \\
7\end{array}$ & $\begin{array}{l}10 \\
.3\end{array}$ & 5.0 & $\begin{array}{ll}10 \\
0\end{array}$ \\
\hline $\begin{array}{l}\text { Candidates that are shortlisted usually have the relevant qualifications and } \\
\text { experience for the job }\end{array}$ & $\begin{array}{l}20 . \\
5\end{array}$ & $\begin{array}{l}38 \\
.5\end{array}$ & $\begin{array}{l}7 . \\
6\end{array}$ & $\begin{array}{l}23 \\
.1\end{array}$ & $\begin{array}{l}10 . \\
3\end{array}$ & $\begin{array}{l}10 \\
0\end{array}$ \\
\hline $\begin{array}{l}\text { The same s. election tool is used for all the candidates applying for the same } \\
\text { position }\end{array}$ & $\begin{array}{l}25 . \\
6\end{array}$ & $\begin{array}{l}35 \\
.9\end{array}$ & $\begin{array}{l}15 \\
.4\end{array}$ & $\begin{array}{l}12 \\
.8\end{array}$ & $\begin{array}{l}10 . \\
3\end{array}$ & $\begin{array}{l}10 \\
0\end{array}$ \\
\hline Nepotism and tribalism is not a factor when hiring decisions are made & $\begin{array}{l}25 . \\
6\end{array}$ & $\begin{array}{l}23 \\
.1\end{array}$ & $\begin{array}{l}10 \\
.3\end{array}$ & $\begin{array}{l}15 \\
.4\end{array}$ & $\begin{array}{l}25 . \\
6\end{array}$ & $\begin{array}{l}10 \\
0\end{array}$ \\
\hline $\begin{array}{l}\text { Some candidates are hired without going through the formal recruitment and } \\
\text { selection process }\end{array}$ & $\begin{array}{l}15 . \\
4\end{array}$ & $\begin{array}{l}28 \\
.2\end{array}$ & $\begin{array}{l}12 \\
.8\end{array}$ & $\begin{array}{l}15 \\
.4\end{array}$ & $\begin{array}{l}28 . \\
2\end{array}$ & $\begin{array}{l}10 \\
0\end{array}$ \\
\hline $\begin{array}{l}\text { Public interest and organizational interest are always placed over personal } \\
\text { interest when making recruitment and selection decisions }\end{array}$ & $\begin{array}{l}25 . \\
6\end{array}$ & $\begin{array}{l}30 \\
.8\end{array}$ & $\begin{array}{l}10 \\
.3\end{array}$ & $\begin{array}{l}30 \\
.7\end{array}$ & 2.6 & $\begin{array}{l}10 \\
0\end{array}$ \\
\hline The organization has an ethics committee that offers adv & 35 & 11 & 14 & 22 & 19 & $\begin{array}{l}10 \\
0\end{array}$ \\
\hline
\end{tabular}

\subsection{Inferential statistics}

Correlation analysis was carried out to determine the relationship between ethical hiring practices and ethical legislative and policy framework. The results that were obtained as shown in table 2 showed that there is a positive and significant linear relationship between ethical hiring practices and ethical legislative framework with a Pearson correlation coefficient of 0.693 and a p- value of 0.000 . These findings show that an ethical legislative and policy framework has a strong positive relationship with ethical hiring practices in organizations. This implies that an increase in ethical policy and legislative framework helps to increase ethical hiring by providing ethical guidelines when making hiring decisions.

\section{Table 2: Correlation}

\begin{tabular}{|c|c|c|c|}
\hline & & $\begin{array}{c}\text { Ethical Hiring } \\
\text { practices }\end{array}$ & $\begin{array}{l}\text { Ethical and legislative } \\
\text { framework }\end{array}$ \\
\hline \multirow{4}{*}{ Ethical Hiring practices } & Pearson & $\mathrm{P}=000 \mathrm{~s}$ & $.693^{* *}$ \\
\hline & Correlation & & \\
\hline & Sig. (2-tailed) & & .000 \\
\hline & $\mathrm{N}$ & 39 & 39 \\
\hline \multirow{4}{*}{$\begin{array}{l}\text { Ethical legislative and policy } \\
\text { framework }\end{array}$} & Pearson & $.693^{* *}$ & 1 \\
\hline & Correlation & & \\
\hline & Sig. (2-tailed) & .000 & \\
\hline & $\mathrm{N}$ & 39 & 39 \\
\hline
\end{tabular}

\footnotetext{
**. Correlation is significant at the 0.01 level (2-tailed).
}

Finding in table 3 on regression analysis showed that show that ethical policy and legislative framework has an R square value of 0.480 which means that ethical policy and legislative framework contributes $48 \%$ to ensuring that there is ethical hiring in organizations or $48 \%$ of ethical hiring can be explained by having ethical legislative and policy framework, $52 \%$ can be explained by other factors. 
Table 3: Regression analysis

\begin{tabular}{lrrrr}
\hline Model & R & R Square & Adjusted R Square & Std. Error of the Estimate \\
\hline 1 & $.693^{\mathrm{a}}$ & .480 & .466 & .4958 \\
\hline
\end{tabular}

a. Predictors: (Constant), Ethical policy and Legislative framework

The findings from the standardized and unstandardized coefficient of regression as shown in table 4 indicate that $\mathrm{B}_{0}$ is 1.699 units. This can be interpreted as meaning that when there is no ethical legislative and policy framework, the model predicts that ethical hiring practices will have 1.699 units, but when ethical legislative and policy framework is introduced then ethical recruitment and selection increases by 0.467 units or $46.7 \%$ This means that $46.7 \%$ of ethical hiring practices can be attributed to ethical legislative and policy framework. The research hypothesis that; legislative and policy framework has no significant effect on ethical hiring practices in selected organizations in Kenya is therefore rejected.

The regression obtained was;

Ethical Hiring $=1.699+0.467$ (ethical legislative and policy framework) $+\mathrm{e}$

Table 4: Coefficients of Regression

\begin{tabular}{llrrrrr}
\hline Model & & Unstandardized Coefficients & \multicolumn{2}{c}{$\begin{array}{c}\text { Standardized } \\
\text { Coefficients } \\
\text { Beta }\end{array}$} & t & Sig. \\
& B & Std. Error & Beta & \\
\hline & (Constant) & 1.699 & .304 & & 5.590 & .000 \\
1 & Ethical Legislative and Policy & .467 & .080 & .693 & 5.844 & .000
\end{tabular}

framework

a. Dependent Variable: Ethical Hiring

This is in agreement with a research work done by Creighton as cited by Pinnington, Macklin, and Campbell (2007) on "Human Resource Management, ethics and employment" that ethical legislature and policies cannot enforce ethical behavior but it can only provide guidelines to promote ethical behavior and offer limited protection against unlawful HR practices such as discrimination during hiring. Some of the ethical guidelines for ethical hiring according to Tordoff (2017), in a paper on ethical recruitment guidelines include; having transparent recruitment and selection practices, getting many people to apply for a position so as to make the best selection decisions, , following the laid down rules and policies as well as to mention a few. However according to Nguyen (2013), following the law and policies when making selection decisions is not enough to ensure that ethical hiring is done, managers also need to be ethically sensitive to avoid engaging in unethical hiring practices.

\section{Conclusions}

The study sought to establish if ethical legislative and policy framework has a relationship with ethical hiring practices, based on the findings the study concludes that ethical legislative and policy framework plays a key role in ensuring that ethical hiring decisions are done. This is because it provides guidelines that should be followed during the hiring process so as to ensure that hiring is not based on any form of discrimination and only those candidates that fit the job are hired on merit. However legislation and policies on ethics cannot ensure ethical hiring, managers need to be ethically sensitive when they meet ethical dilemmas during hiring to ensure that hiring is both legal and ethical.

This study recommends that managers need to ensure that they follow the laid down ethical laws and policies which can act as a guideline when making hiring decisions so as to ensure that they don't engage in unethical hiring practices. In addition, they need to be ethically sensitive so as to ensure that they don't engage in any hiring practices that may appear legal but is unethical.

Suggestions for further study include studies and research on how to conduct "ethical due diligence" within the Kenyan context when making hiring decisions so as to ensure that the candidates hired are ethical and fit with the ethical culture and ethical values of the organization, as well as studies on legal but unethical HR practices in Kenyan organizations.

\section{References}

Alder. S. G and Gilbert, J. (2006). Achieving Ethics and Fairness in Hiring: Going Beyond the Law Journal of Business Ethics .68 (4):449-464 (2006)

Boardman, J \& Barbato, C. (2008). Review of socially responsible HR and labour relations practice in international hotel chains. Working Paper. 267. International Labour Office Geneva, June 2008. ISBN: 9789221217060

Bratton, J., \& Gold, J. (2007). Human Resource Management: Theory and Practice, 4th Edition, Houndmills: Macmillan.

CIPD (2015). From best to good practice HR: Developing principles for the profession. CIPD Research report. London: CIPD. Available at: http://www.cipd. co.uk.

Gommans, P, H. \&Musumbu, J.M. (2014). The Role of Ethical Practice in Recruitment in Improving Performance 
of an Institution; A case study of ethics in recruitment of the police service in Kenya and resultant performance in stemming insecurity since 2010). International Journal of Scientific and Research Publications, Volume 4, Issue 10, October 20141 ISSN 2250-3153

International Federation of Accountants (IFAC), (2007). Defining and Developing an Effective Code of Conduct for Organizations. International Good Practice Guidance. A publication by Professional Accountants in Business Committee. New York, U.S.A

Karren, R. J. and Zacharias, L. (2007). Integrity tests: Critical issues, Human Resource Management Review, 17, 221-234

Murage, S., Sang, A. and Ngure,S. (2018). Ethical Issues in Recruitment, Selection and Employee Performance in Public Universities in Nyeri County, Kenya. International Journal of Business and Social Science, Volume 9, ISSN 2219-1933 (Print), 2219-6021 (Online

Nguyen. T,N. (2013). Ethics in Employee Selection: What You Want to Know but are Afraid to Ask. Journal of Business \& Financial Affairs. ISSN: 2167-0234. Volume 2 - Issue 1

Onyeaghala. O,H, and Hyacinth, M.I (2016). Effects of Employee Selection Process on Productivity in the Public and Private Sectors: A Case of Benue State. Bus Eco J 7:273. doi: 10.4172/2151-6219.1000273

Ouma,C. (2017). Ethical Leadership and Organizational Culture: Literature Perspective. INTERNATIONAL JOURNAL OF INNOVATIVE RESEARCH \& DEVELOPMENT. ISSN 2278 - 0211 (Online)

Pinnington, Macklin, and Campbell (2007) on "Human Resource Management, ethics and employment”. Oxford University Press, UK

Tordoff, J. (2017).Transforming Surge Capacity. Ethical Recruitment Guidelines. Start network. Retrieved from www.chsalliance.org/files/files/Resources

Valentine, Nam, Hollingworth and Hall (2013). Ethical Context and Ethical Decision Making: Examination of an Alternative Statistical Approach for Identifying Variable Relationships. Journal of Business Ethics. Retrieved from : https://www.researchgate.net/publication/271658267

Wheeler, K. (2004). The Ethics of Recruiting. Ere Recruiting Intelligence. As retrieved fromhttps://www.ere.net/the-ethics-of-recruiting/ 